\title{
Clinical and Endoscopic Features of Colonic Anisakiasis in Korea
}

\author{
Sae Kyung Joo†, Ji Won Kim, Byeong Gwan Kim, Won Kim, Jae Kyung Lee, Kook Lae Lee* \\ Seoul National University Seoul Metropolitan Government Boramae Medical Center - Internal Medicine, Seoul 07061, Korea
}

\begin{abstract}
To analyze the clinical and endoscopic features of colonic anisakiasis. A retrospective chart review of 20 patients with colonic anisakiasis, who were diagnosed by colonoscopy at 8 hospitals between January 2002 and December 2011, was performed. Patients' mean age was 53.6 \pm 10.74 years. Seventy percent patients were men. Acute abdominal pain was a common symptom that mostly developed within $48 \mathrm{hr}$ after the ingestion of raw fish, and which lasted for 1-28 days. Sixty percent patients had ingested raw fish before the diagnosis of colonic anisakiasis and $40 \%$ patients were incidentally found to have colonic anisakiasis during the screening colonoscopies. Leukocytosis and eosinophilia were each found in $20 \%$ of the patients. In all patients who underwent colonoscopy, the worms were removed with biopsy forceps, except in 1 case, and a definite diagnosis of anisakiasis was made. In some cases of colonic anisakiasis, colonoscopy may be helpful in the diagnosis and treatment to avoid surgical intervention.
\end{abstract}

Key words: Anisakiasis, colon, colonoscopy, biopsy

\section{INTRODUCTION}

Anisakis is a nematode parasite that may infect humans following the ingestion of uncooked or raw, infected seafood, such as herring, squid, anchovy, cod, mackerel, and pacific salmon [1]. Most cases of anisakiasis are reported from countries where the consumption of raw seafood is common, such as East Asian and Southern European countries, but the incidence of anisakiasis is increasing worldwide because of the increased popularity of sushi and sashimi. When humans ingest this infected seafood, the Anisakis larvae can migrate to the digestive tract and potentially invade the gastric and intestinal walls where they cause various symptoms such as abdominal pain, nausea, vomiting, and diarrhea [2]. Anisakiasis is classified according to the infected organ or anatomical location, e.g., gastric anisakiasis and enteric anisakiasis [3]. The stomach is the most commonly involved site, followed by the small intestine; the colon is rarely affected [4].

Most reports describe symptomatic patients as those having an obstruction or peritonitis $[5,6]$. Laparotomy leads to the

- Received 23 May 2019, revised 22 July 2019, accepted 12 August 2019

*Corresponding author (kllee@brmh.org)

${ }^{\dagger}$ These authors contributed equally to this work.

(c) 2019. Korean Society for Parasitology and Tropical Medicine

This is an Open Access article distributed under the terms of the Creative Commons Attribution Non-Commercial License (http://creativecommons.org/licenses/by-nc/4.0) which permits unrestricted non-commercial use, distribution, and reproduction in any

medium, provided the original work is properly cited. identification of an Anisakis worm in the excised specimen of the small intestine or colon. A case of peritonitis in Japan was confirmed to be an Anisakis infection, following partial resection of the ileum [5]. In another published case, intestinal obstruction was found to have been caused by acute invasive enteric anisakiasis, which was confirmed by segmental resection of the small bowel [6]. The presence of Anisakis worms can also be detected by colonoscopy in asymptomatic patients [7]. However, only a few cases of colonic anisakiasis have been reported [8], and the clinical features and treatment of this condition remain unclear. Therefore, this study investigated the clinical and endoscopic features of colonic anisakiasis by colonoscopy in Korea.

\section{CASE RECORD}

Patients diagnosed as having colonic anisakiasis following colonoscopy at 7 University hospitals (Seoul National University College of Medicine Boramae Medical Center, University of Ulsan College of Medicine Asan Medical Center, Sungkyunkwan University School of Medicine Samsung Medical Center, Seoul National University Bundang Hospital, Chungang University College of Medicine, Catholic University College of Medicine, and Wonkwang University College of Medicine) and One General Hospital (St. Luke's Hospital) in Korea between January 2002 and December 2011 were enrolled in 
this chart review study. The medical records of the 20 patients diagnosed as having colonic anisakiasis were retrospectively reviewed, and the following parameters were analyzed: age, sex, type of raw seafood ingested, clinical symptoms, interval between raw seafood ingestion and onset of symptoms, laboratory findings, such as leukocyte and eosinophil counts, radiologic findings, colonoscopic findings, location at which the Anisakis larvae were found, and treatment. Anisakiasis was identified in histologic section by pathologist as following characteristics, (1) distinctive Y-shaped lateral chords; (2) no lateral alae (wing like projection) extending from cuticles as with larval Ascaris sp.; and (3) 60 to 90 muscle cells per quadrant; 60 to 80 cells in the intestine [2].

\section{Statistical analysis}

SPSS 18.0 software (SPSS, Chicago, Illinois, USA) was used to perform the statistical analysis. Patients were divided into 2 groups according to their clinical symptoms: acute colonic anisakiasis or incidental anisakiasis. Data are presented as means \pm standard deviation or frequencies (percentages). The Student $t$-test, $\chi^{2}$ test, and Fisher exact test were used to analyze continuous and categorical variables, and $P<0.05$ was considered significant in all analyses.

\section{Clinical features}

The patients (70\% men and 30\% women) ranged in age from 32 to 71 years (mean, $53.6 \pm 10.74$ years). Abdominal symptoms were present in $60 \%$, and $40 \%$ patients were asymptomatic. Overall, acute abdominal pain was the most common symptom; some patients also experienced nausea, vomiting, and/or diarrhea. These symptoms mostly developed within $48 \mathrm{hr}$ after ingestion of raw fish and lasted for 1-28 days (Table 1). Seventy five percent of the 12 patients with abdominal symptoms and $25 \%$ of the 8 asymptomatic patients reported a history of raw fish ingestion before their diagnosis of colonic anisakiasis. Forty percent patients were incidentally found to have a colonic infection of Anisakis larvae during screening colonoscopic examinations (Table 1; Supplementary Table S1).

\section{Laboratory and radiologic findings}

Leukocytosis was found in 20\%, and eosinophilia in 20\% (Table 1). Of the 20 patients, radiographic data of $25 \%$ patients were studied; $5 \%$ patient had ileus, and the remaining $20 \%$ patients had a normal abdomen. Among the 20 patients,
Table 1. Baseline characteristics $(n=20)$

\begin{tabular}{|c|c|}
\hline & Patients, \% \\
\hline Sex & $\begin{array}{l}\text { Male, } 70.0 \\
\text { Female, } 30.0\end{array}$ \\
\hline Age (yr), mean $\pm S D$ (range) & $53.6 \pm 10.74(32-71)$ \\
\hline Type of raw fish & $\begin{array}{l}\text { Conger, } 10 \\
\text { Skate, } 10 \\
\text { Yellowtail, } 5 \\
\text { Flatfish, } 5 \\
\text { Crayfish, } 5 \\
\text { Undetermined, } 20 \\
\text { NA, } 45\end{array}$ \\
\hline $\begin{array}{l}\text { Time from ingestion of raw fish to } \\
\text { onset of symptoms (hr) }\end{array}$ & $\begin{array}{l}\leq 12,5 \\
>12 \leq 24,5 \\
>24 \leq 48,10 \\
>48,25 \\
\text { NA, } 15 \\
\text { Incidental, } 40\end{array}$ \\
\hline Clinical symptoms ${ }^{a}$ & $\begin{array}{l}\text { Abdominal pain, } 35 \\
\text { RLQ pain, } 10 \\
\text { Lower abdomen pain, } 10 \\
\text { Periumbilical pain, } 5 \\
\text { NA, } 10 \\
\text { Hematochezia, } 5 \\
\text { Diarrhea, } 5 \\
\text { Stool caliber change, } 10 \\
\text { Dyspepsia, } 5 \\
\text { Nausea or vomiting, } 10 \\
\text { Health checkup, } 40\end{array}$ \\
\hline Location & $\begin{array}{l}\text { Cecum and ascending colon }{ }^{\mathrm{b}}, 60 \\
\text { Transverse colon, } 20 \\
\text { Descending colon, } 10 \\
\text { Sigmoid colon, } 10 \\
\text { Rectum, } 5\end{array}$ \\
\hline Leukocytosis & $\begin{array}{l}\text { Yes, } 20 \\
\text { No, } 80\end{array}$ \\
\hline Eosinophilia & $\begin{array}{l}\text { Yes, } 20 \\
\text { No, } 80\end{array}$ \\
\hline Treatment & $\begin{array}{l}\text { Endoscopic removal, } 95 \\
\text { Medication, } 5\end{array}$ \\
\hline
\end{tabular}

SD, standard deviation; NA, not available; NS, not significant; RLQ, right lower quadrant.

aData are overlapped.

${ }^{\mathrm{b}}$ Appendix is included.

$25 \%$ underwent contrast-enhanced abdominal computed tomography before colonoscopic removal of the Anisakis larvae. They showed edematous changes of the enteric walls, including thickened folds at the site of infection. No narrowing of the lumen or ascites was detected.

\section{Endoscopic findings}

In all patients, colonoscopy was performed within $24 \mathrm{hr}$ after visiting the hospital, and anisakiasis was diagnosed by observation of the worms during the colonoscopic examination. Localized mucosal edema and erythema were observed in 
Table 2. Comparison of laboratory, radiologic, and colonoscopic findings between the acute anisakiasis and incidental anisakiasis groups

\begin{tabular}{|c|c|c|c|}
\hline & $\begin{array}{c}\text { Acute } \\
\text { anisakiasis (\%) } \\
60 \%(n=12)\end{array}$ & $\begin{array}{c}\text { Incidental anisakiasis (\%) } \\
40 \%(n=8)\end{array}$ & $P$-value \\
\hline \multicolumn{4}{|l|}{ Laboratory Findings } \\
\hline Leukocytosis & 33.3 & 0 & 0.068 \\
\hline Eosinophilia & 25.0 & 12.5 & 0.494 \\
\hline \multicolumn{4}{|l|}{ Radiologic Findings } \\
\hline lleus on X-ray & 16.7 & 0 & 0.224 \\
\hline Mucosal thickening detected by computed tomography & 33.3 & 0 & 0.068 \\
\hline \multicolumn{4}{|l|}{ Colonoscopic Findings } \\
\hline Edematous mucosa with erythema & 41.7 & 37.5 & 0.852 \\
\hline \multicolumn{4}{|l|}{ Location } \\
\hline Left colon & 8.3 & 25.0 & 0.537 \\
\hline Right colon & 91.7 & 75.0 & \\
\hline
\end{tabular}

$50 \%$ of patients. Anisakis larvae were found in the cecum and ascending colon in $60 \%$ of patients, transverse colon in $20 \%$, descending colon in $10 \%$, sigmoid colon in $5 \%$, and rectum in $5 \%$. The worms were removed using biopsy forceps, except in 1 case. In that case, the patient was treated with oral albendazole (Table 1). After colonoscopic removal, the abdominal pain disappeared within a few hours.

After dividing the patients into 2 groups according to whether they had acute anisakiasis or asymptomatic anisakiasis (Table 2), we did not find a statistical difference in laboratory, radiologic, and colonoscopic findings between the groups. However, edematous mucosal changes and wall thickening of the bowel detected by computed tomography and colonoscopy were more common in the acute anisakiasis group than in the asymptomatic anisakiasis. The Anisakis larvae were mainly found in the right colon in both groups.

\section{DISCUSSION}

This study demonstrated that some patients with colonic anisakiasis can be diagnosed by colonoscopy before intestinal obstruction or perforation occurs. In some patients, biopsy forceps were used to remove the Anisakis worms, demonstrating that diagnosis and treatment can be performed simultaneously in some instances.

According to a series of 15,715 cases reported by Ishikura [9], gastric anisakiasis accounted for $95.6 \%$ of Anisakis infections, enteric anisakiasis for $4.1 \%$, and other sites for $0.3 \%$. Mineta et al. [10] performed a meta-analysis of 30,000 reported cases of anisakiasis in Japan and found only $0.25 \%$ of colonic ani- sakiasis. The most reasonable explanation for the rarity of colonic infection is that the colon is too far from the mouth for the orally ingested larvae to reach $[10,11]$. The location of larval invasion is affected by the amount and frequency of food intake, fullness of the patient's stomach, and excretion capacity and digestive power of the digestive tract. Among the 75 reported cases of colonic infection, Anisakis larvae were found on the right side of the colon in more than half of the cases. Similarly, in the current study, $65 \%$ of patients were also found to have the Anisakis larvae on the right side of the colon. The more frequent involvement of the right side of the colon can be explained by the gradual peristalsis and slow transit in the colon, which allows the larvae to infect while remaining in the right side of the colon [11]. When a digestive disorder exists, symptoms can occur within a few hours of consumption the contaminated, raw fish.

The most important clinical clue for the diagnosis of colonic anisakiasis is a history of raw marine fish ingestion. In our study, 55\% patients had a history of consuming raw fish. Clinical manifestations of colonic anisakiasis are nonspecific; patients may present with symptoms as diverse as colic and diffuse abdominal pain, nausea, vomiting, and diarrhea [12]. In our study, 35\% patients complained of these types of symptoms, which explains why patients with colonic anisakiasis are often misdiagnosed as having acute appendicitis or diverticulitis [12]. Clinical symptoms appear within $48 \mathrm{hr}$ after ingestion of the contaminated meat and continue for 1-5 days with spontaneous recovery often occurring [13]. Except in 3 patients in our study, most patients' symptoms occurred within a similar period. 
On the contrary, gastric anisakiasis presents with acute severe epigastric pain few hours after the ingestion of raw seafood infested by Anisakis larvae. The symptoms usually occur within $12 \mathrm{hr}$. It takes a shorter time for symptoms to manifest compared to colonic anisakiasis $[14,15]$. Other clinical manifestations include nausea, vomiting, and low-grade fever. There are cases in which the patients present with hematemesis from gastric ulceration [15-20].

Laboratory examinations may demonstrate the presence of leukocytosis, especially if there are complications, such as ileus perforation or peritonitis; additionally, an increased eosinophil count may be observed 8-15 days after parasitic ingestion. However, eosinophilia is not always observed at the onset of the symptom or specific to anisakiasis [21]. In our cases, neutrophilia was found in $20 \%$ of patients, and eosinophilia was found in $20 \%$. A plain abdominal X-ray is also non-specific, and radiology of the small bowel may aggravate the clinical symptoms. Despite recent advances in various imaging techniques, such as ultrasonography, computed tomography, and magnetic resonance imaging, it remains difficult to make a definite diagnosis of small intestinal and colonic anisakiasis. However, the radiographic features of intestinal or colonic anisakiasis are characterized by edematous changes of the enteric walls, including thickened folds, a "thumb-print" appearance, saw-toothed aspect, an irregular narrowing of the lumen, and the disappearance of the Kerckring folds [7,22]. These findings may be helpful for the diagnosis of anisakiasis in the small intestine or colon, but it is not always specific [22]. In our study, we observed edematous mucosal change, hyperemia, or erosion by colonoscopy in $35 \%$ patients. These are common colonoscopic findings in Anisakis infection. Additionally, luminal stricture and mucosal hemorrhage is observed, but these are nonspecific findings.

In patients with gastric anisakiasis, endoscopic removal of the larvae sticking to the gastric wall is usually curative without the need for further treatment because there is often only a single worm in most patients [1]. In cases of colonic anisakiasis, colonoscopic removal of the infecting organisms has been rarely been reported [23]. Because the Anisakis larvae die over time, i.e., after passing through the stomach and small intestine, colonic anisakiasis is generally treated conservatively [24]. Moreover, surgical treatment is needed only in cases of intestinal obstruction or acute peritonitis [25]. In our cases, the diagnosis and treatment of colonic anisakiasis was performed in 95\% patients; the larvae were found and removed by colonoscopy. Only 1 patient was treated with albendazole. The physician could not diagnose colonic anisakiasis, until an Anisakis larva was detected by colonoscopy. Because severe edematous mucosa, erosion, and a polyp-like lesion were found by colonoscopy, the physician prescribed albendazole for empirical treatment later. The symptom and colonoscopic finding improved after the patient took the medication.

Patients with colonic anisakiasis were divided into 2 groups according to their symptoms at onset: acute anisakiasis and incidental anisakiasis. Patients with acute anisakiasis complained of acute abdominal pain, and they visited the hospital and were diagnosed by colonoscopy. Patients with incidental anisakiasis were asymptomatic and diagnosed based on screening colonoscopy findings. When the clinical and other features of the 2 groups of patients were compared, leukocytosis and eosinophilia were more frequent in the acute anisakiasis group than in the incidental anisakiasis group. Mucosal thickening detected by computed tomography and edematous mucosa detected by colonoscopy were also more prevalent in the acute anisakiasis group than in the incidental anisakiasis group. However, there were no significant differences in laboratory, radiologic, and colonoscopic findings between the groups. Regardless, most larvae were located in the right colon in both groups.

The symptoms of colonic anisakiasis are vague, and this condition is often misdiagnosed. Matsumoto et al. [11] reported that colonic anisakiasis is misdiagnosed preoperatively as

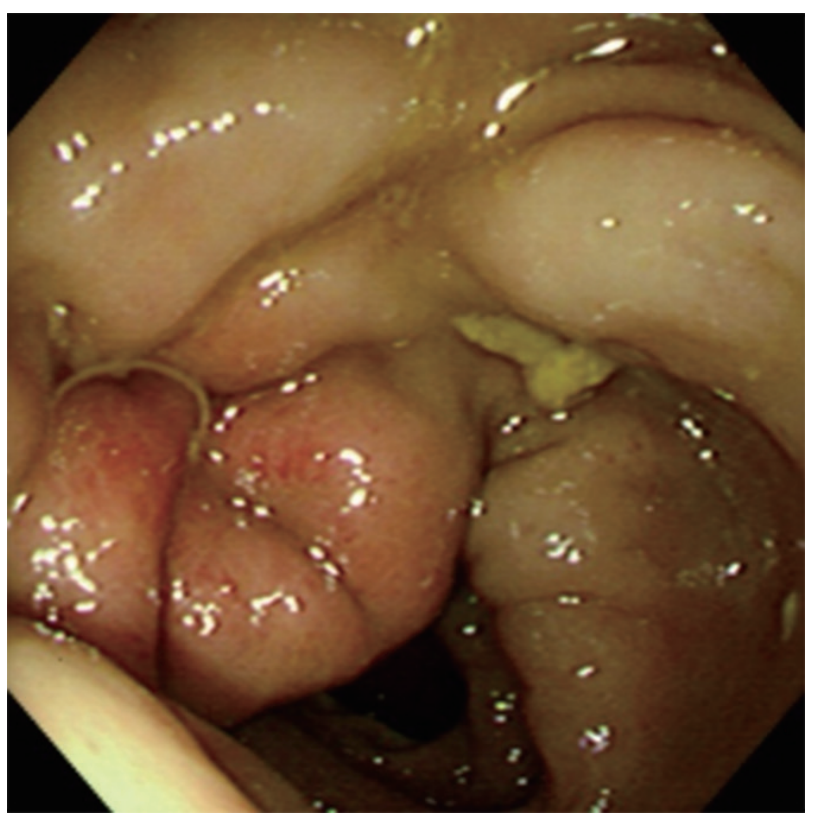

Fig. 1. Colonoscopic findings of anisakiasis in case no. 12. 
acute appendicitis, cancer, ileitis, and diverticulitis. In a retrospective study in Japan, Hayasaka et al. [12] found that anisakiasis was often misdiagnosed as Crohn's disease. In our patients, the 8 asymptomatic patients were diagnosed as having colonic anisakiasis during screening colonoscopies. Prior cases of asymptomatic colonic anisakiasis have not been reported in Korea. Differential diagnoses must be carefully considered for trichuriasis and colonic anisakiasis by colonoscopy.

Larval Anisakis are grossly visible, measuring approximately 2-2.5 $\times 0.1-0.2 \mathrm{~cm}$. In colonic anisakiasis, colonoscopic findings show hyperemic and edematous mucosal changes due to colonic wall invasion by the larvae (Fig. 1). Regardless, morphologic proof of an Anisakis larva in the resected specimen is the best basis for a diagnosis [26]. In histological sections, Anisakis larvae have distinctive Y-shaped lateral cords, 60-90 muscle cells per quadrant, and no lateral alae or wing-like projections extending from the cuticle, similar to Ascaris larvae [1].

Our study included cases of anisakiasis of several hospital, which is not equivalent to the true anisakiasis incidence or characteristics in the general population. Individual data such as occupation and/or other possible related risk factors are not included. However, by colonoscopic examination we correctly diagnosed intestinal anisakiasis and avoided unnecessary surgical intervention.

In conclusion, early colonoscopic examinations may be helpful in the diagnosis and treatment of colonic anisakiasis when the patient has a history of ingestion of raw fish. In addition, colonic anisakiasis may be diagnosed by colonoscopy when an asymptomatic patient has a history of eating of raw fish.

\section{ACKNOWLEDGMENTS}

This study was approved by the institutional review board of Seoul National University Boramae Hospital (IRB No. 06-2011143). We thank Woo Bong Choi (St. Luke's Hospital, Seocheon, Korea), Tae Hyeon Kim (Wonkwang University College of Medicine, Iksan, Korea), Dong Soo Lee (Catholic University College of Medicine, Seoul, Korea), Jeong Wook Kim (Chungang University College of Medicine, Seoul, Korea), Na Young Kim (Seoul National University Bundang Hospital, Seongnam, Korea), Byung Duk Ye (University of Ulsan College of Medicine Asan Medical Center, Seoul, Korea), and Jun Haeng Lee (Sungkyunkwan University School of Medicine Samsung Medical Center, Seoul, Korea) for assisting with the data.

\section{CONFLICT OF INTEREST}

All authors declare no conflict of interest for this article.

\section{REFERENCES}

1. Sakanari JA. Anisakiasis. In Connor DH, Chandler FW, Schwartz DA, Lack EE, Manz H eds. Pathology of Infectious Diseases. Stamford, USA. Appleton \& Lange. 1997, pp 1315-1320.

2. Sakanari JA, McKerrow JH. Anisakiasis. Clin Microbiol Rev 1989; 2: 278-284.

3. Ishida $\mathrm{M}$, Harada $\mathrm{A}$, Egawa $\mathrm{S}$, Watabe $\mathrm{S}$, Ebina $\mathrm{N}$, Unno M. Three successive cases of enteric anisakiasis. Dig Surg 2007; 24: 228-231.

4. Chikamori F, Kuniyoshi N, Takase Y. Intussusception due to intestinal anisakiasis: a case report. Abdom Imaging 2004; 29: 2941.

5. Sugita S, Sasaki A, Shiraishi N, Kitano S. Laparoscopic treatment for a case of ileal anisakiasis. Surg Laparosc Endosc Percutan Tech 2008; 18: 216-218.

6. Kang DB, Oh JT, Park WC, Lee JK. Small bowel obstruction caused by acute invasive enteric anisakiasis. Korean J Gastroenterol 2010; 56: 192-195 (in Korean).

7. Kim SJ, Kim JW, Kim KJ, Heo C, Kim SW, Han SP, Seo YH, Do JH, Kim JG, Park SM. Two cases of colon anisakiasis: asymphtomatic cecal anisakiasis and ascending colon anisakiasis detected one month later after infestation. Korean J Gastrointest Endosc 2006; 33: 116-120.

8. Caramello P, Vitali A, Canta F, Caldana A, Santi F, Caputo A, Lipani F, Balbiano R. Intestinal localization of anisakiasis manifested as acute abdomen. Clin Microbiol Infect 2003; 9: 734737.

9. Ishikura H. Anisakis. Clin Gastroenterol 1991; 6: 1052-1060 (in Japanese).

10. Mineta S, Shimanuki K, Sugiura A, Tsuchiya Y, Kaneko M, Sugiyama Y, Akimaru K, Tajiri T. Chronic anisakiasis of the ascending colon associated with carcinoma. J Nippon Med Sch 2006; 73: 169-174.

11. Matsumoto T, Iida M, Kimura Y, Tanaka K, Kitada T, Fujishima M. Anisakiasis of the colon: radiologic and endoscopic features in six patients. Radiology 1992; 183: 97-99.

12. Hayasaka $H$, Ishikura $H$, Takayama $T$. Acute regional ileitis due to anisakis larvae. Int Surg 1971; 55: 8-14.

13. Pellegrini M, Occhini R, Tordini G, Vindigni C, Russo S, Marzocca G. Acute abdomen due to small bowel anisakiasis. Dig Liver Dis 2005; 37 : 65-67.

14. Takabayashi T, Mochizuki T, Otani N, Nishiyama K, Ishimatsu S. Anisakiasis presenting to the ED: clinical manifestations, time course, hematologic tests, computed tomographic findings, and treatment. Am J Emerg Med 2014: 32: 1485-1489.

15. Lee EJ, Kim YC, Jeong HG, Lee OJ. The mucosal changes and influencing factors in upper gastrointestinal anisakiasis: analysis of 
141 cases. Korean J Gastroenterol 2009; 53: 90-97 (in Korean).

16. Takeuchi K, Hanai H, Iida T, Suzuki S,Isobe S. A bleeding gastric ulcer on a vanishing tumor caused by anisakiasis. Gastrointest Endosc. 2000; 52: 549-551.

17. Sohn WM, Na BK, Kim TH, Park TJ. Anisakiasis: report of 15 gastric cases caused by Anisakis type I larvae and a brief review of Korean anisakiasis cases. Korean J Parasitol 2015; 53: 465470.

18. Yoon WJ, Lee SM, Lee SH, Yoon YB. Gastric anisakiasis. Gastrointest Endosc 2004; 59: 400.

19. Kang DB, Park WC, Lee JK. Chronic gastric anisakiasis provoking a bleeding gastric ulcer. Ann Surg Treat Res 2014; 86: 270-273.

20. Goto Y, Takahashi N, Yoshlmitsu M, Matano Y. A case of gastric anisakiasis with hemorrhagic gastric ulcer and ulcerative scarring. Nihon Shokakibyo Gakkai Zasshi 2014; 111: 2021-2024 (in Japanese).
21. Matsui T, Iida M, Murakami M, Kimura Y, Fujishima M, Yao Y, Tsuji M. Intestinal anisakiasis: clinical and radiologic features. Radiology 1985; 157: 299-302.

22. Sugita S, Sasaki A, Shiraishi N, Kitano S. Laparoscopic treatment for a case of ileal anisakiasis. Surg Laparosc Endosc Percutan Tech 2008; 18: 216-218.

23. Minamoto T, Sawaguchi K, Ogino T, Mai M. Anisakiasis of the colon: report of two cases with emphasis on the diagnostic and therapeutic value of colonoscopy. Endoscopy 1991; 23: 50-52.

24. Takei H, Powell SZ. Intestinal anisakidosis (anisakiosis). Ann Diagn Pathol 2007; 11: 350-352.

25. Deardorff TL, Kayes SG, Fukumura T. Human anisakiasis transmitted by marine food products. Hawaii Med J 1991; 50: 9-16.

26. Elliott DE. Intestinal worms. In Feldman M, Friedman LS, Brandt LJ. Sleisenger \& Fordtran's Gastrointestinal and Liver Disease. 8th ed. Pennsylvania, USA. Saunders. 2006, pp 2441-2442. 
Supplementary Table S1. Baseline characteristics of the enrolled patients by individual case

\begin{tabular}{lccclc}
\hline Case No. & Age & Sex & Date of occurrence & \multicolumn{1}{c}{ Chief Complaints } & Fish Eaten \\
\hline 1 & 37 & 1 & $2011-04-27$ & Abdomen pain & Yes \\
\hline 2 & 50 & 2 & $2004-01-14$ & Abdomen pain & No \\
\hline 3 & 64 & 1 & $2007-12-18$ & Abdomen pain & No \\
\hline 4 & 32 & 1 & $2005-01-03$ & Abdomen pain & Yes \\
\hline 5 & 71 & 1 & $2006-00-00$ & Melena, and dyspepsia & Yes \\
\hline 7 & 36 & 2 & $2006-00-00$ & Abdomen pain & No \\
\hline 8 & 53 & 1 & $2009-12-21$ & Dyspepsia & Yes \\
\hline 9 & 66 & 1 & $2005-01-10$ & Abdomen pain & Yes \\
\hline 10 & 52 & 1 & $2006-00-00$ & Abdomen pain & No \\
\hline 12 & 68 & 1 & $2006-00-00$ & Frequent defecation and stool caliber change & Yes \\
\hline 13 & 54 & 1 & $2006-00-00$ & Abdomen discomfort & No \\
14 & 61 & 2 & $2006-00-00$ & Hematochezia & No \\
15 & 58 & 1 & $2006-00-00$ & Routine check up & No \\
\hline 16 & 45 & 1 & $2006-00-00$ & Routine check up & No \\
\hline 18 & 63 & 2 & $2010-09-15$ & Routine check up & No \\
\hline 19 & 46 & 2 & $2011-07-26$ & Routine check up & No \\
\hline
\end{tabular}

Sex: $1=$ Male, $2=$ Female. 